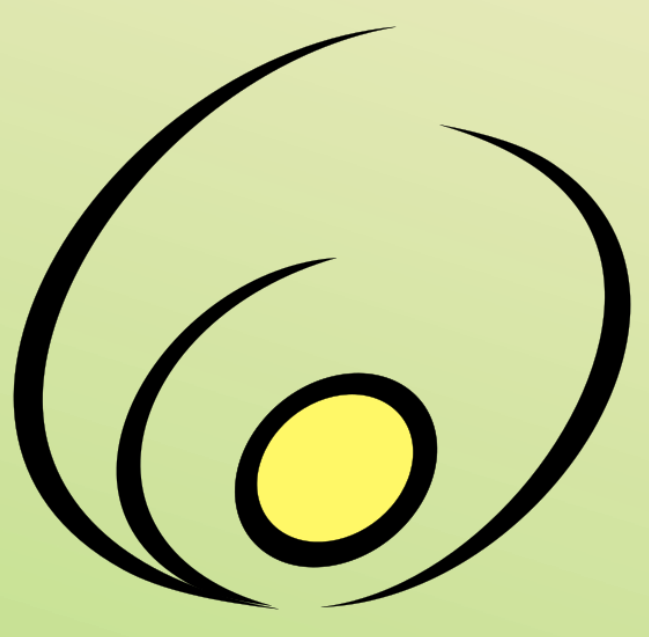

Fórum de

\section{Pró-Reitores}

\section{de Extensão}

\section{das Instituições}

Públicas de

\section{Educação Superior}

\section{Brasileiras}

Revista Brasileira de Extensão Universitária

v. 9, n. 2, p. 75-82 mai.- ago. 2018 e-ISSN 2358-0399

DOI: https://doi.org/10.24317/2358-0399.2018v9i2.7576

originais recebidos em 07 de dezembro de 2017

aceito para publicação em 13 de julho de 2018

\title{
A microbiologia no contexto da
} agroecologia: atividade de extensão junto à Escola Família Agrícola Puris

\author{
Paulo Prates Junior ${ }^{1}$, Marliane de Cássia Soares da Silva², \\ Rita de Cássia Cerqueira Melo ${ }^{3}$, Lorena Azevedo de Lima ${ }^{4}$, \\ Kaliane Sírio Araújo ${ }^{5}$, Isabelle Gonçalves de Oliveira Prado ${ }^{6}$, \\ Cleonice Aparecida Salgado7, José Guilherme Prado Martin ${ }^{8}$
}

Resumo: A extensão universitária tem por objetivo instituir práticas cidadãs de pesquisa e ensino. Nesse contexto, o Núcleo de Estudos em Microbiologia Agrícola (NEMA), da Universidade Federal de Viçosa (UFV), tem desenvolvido atividades de extensão junto à comunidade de Viçosa e região, para o intercâmbio de experiências em pesquisa, ensino e extensão relacionadas à Microbiologia Agrícola. O presente artigo apresenta os primeiros resultados do projeto de extensão universitária desenvolvido pelo NEMA junto à Escola Família Agrícola (EFA) Puris, que adota a Pedagogia da Alternância e tem a Agroecologia como eixo norteador, visando à articulação de atividades práticas e teóricas, em tempos e espaços que se alternam entre a escola e a comunidade na qual os educandos estão inseridos. As três intervenções realizadas até o presente momento abordaram os seguintes temas: demonstração dos micro-organismos no ambiente e o papel das micorrizas; produção, comercialização e consumo de cogumelos; compostagem e produção de alimentos fermentados. No total, as atividades envolveram cerca de 65 educandos do Ensino Médio, 5 monitores da EFA e 24 acadêmicos, dentre os quais professores, técnicos, graduandos e pós-graduandos da UFV. Essas intervenções têm proporcionado um estímulo à curiosidade, antes pouco ofertada, sobre o mundo microbiano e suas aplicações, além de instigar o interesse pelo conhecimento científico e proporcionar novos desafios de ensino e extensão para os acadêmicos envolvidos.

Palavras-chave: Agricultura familiar, Microbiologia agrícola, Universidade Federal de Viçosa

Content shared under Creative Commons Attribution 4.0 Licence CC-BY

1. Biólogo, Me. em Agroecologia, Dr. em Microbiologia Agrícola, Pós-Doutorando, Universidade Federal de Viçosa - UFV junior prates2005@yahoo.com.br

2. Bióloga, Me. e Dr. em Microbiologia Agrícola, Pós-Doutoranda - UFV

3. Bióloga, Me. em Microbiologia Agrícola, Doutoranda em Microbiologia Agrícola - UFV

4. Bióloga, Me. em Biologia Ambiental, Doutoranda em Microbiologia Agrícola - UFV

5. Bióloga, Me. e Dr. em Microbiologia Agrícola - UFV

6. Bióloga, Me. em Microbiologia Agrícola, Doutoranda em Microbiologia Agrícola - UFV

7. Bioquímica, Mestranda em Microbiologia Agrícola - UFV

8. Biólogo, Me. e Dr. em Ciência e Tecnologia de alimentos, Programa de Pós-Graduação em Microbiologia Agrícola, Departamento de Microbiologia, Professor na Universidade Federal de Viçosa -UFV, Edifício Chotaro Shimoya, sala 141, Av. P.H. Rolfs, s/n - Campus Universitário CEP: 36570-900, Viçosa-MG, + 5531 38992553, guilherme.martin@ufv.br (autor para correspondência). 
The microbiology in the context of the agroecology: extension activity in the Puris Agricultural Family School

\begin{abstract}
The university extension aims to establish citizen practices in research and teaching. In this context, the "Núcleo de Estudos em Microbiologia Agrícola (NEMA)", from Universidade Federal de Viçosa - UFV(Viçosa, Minas Gerais State, Brazil), has developed extension activities in Viçosa and region for the exchange of experiences in research, teaching and extension related to Agricultural Microbiology. This paper presents the first results of the university extension project developed by NEMA at the Puris Agricultural Family School (EFA), which adopts the Pedagogy of Alternation for articulating practical and theoretical activities, in times and spaces concatenated between the school and the community in which students are inserted. The three interventions carried out until here were related to the demonstration of microorganisms in the environment and the role of mycorrhizae, the production, marketing and consumption of mushrooms, and the composting and production of fermented foods. In total, about 65 high school students, 5 EFA's monitors and 24 academics and staffs from UFV were involved in the activities. These interventions have provided a stimulus to the curiosity, barely offered before, about the microbial world and their applications. Also, it has instigated the interest for the scientific knowledge and enabled new teaching and extension challenges for the academics involved.
\end{abstract}

Keywords: Family Farming, Agricultural Microbiology, Viçosa Federal University

La microbiología en el contexto de la agroecología: extensión universitaria en la Escuela de la Familia Agrícola Puris

Resumen: La extensión universitaria se caracteriza como un proceso de construcción de relaciones entre la sociedad y la Universidad, con el objetivo de establecer prácticas ciudadanas de investigación y enseñanza. En este contexto, el "Núcleo de Estudos em Microbiologia Agrícola (NEMA)", de la Universidade Federal de Viçosa - UFV (Viçosa, Minas Gerais, Brasil), ha desarrollado actividades de extensión junto a la comunidad de Viçosa y región para el intercambio de experiencias de investigación, enseñanza y extensión relacionadas al área de Microbiología Agrícola. El presente artículo presenta los primeros resultados del proyecto de extensión universitaria desarrollado por el NEMA junto a la Escuela de la Familia Agrícola (EFA) Puris, que adopta la Pedagogía de la Alternancia, buscando la articulación de actividades prácticas y teóricas, en tiempos y espacios que se alternan entre la escuela y la comunidad en la cual los estudiantes están insertados. Las tres intervenciones realizadas hasta el momento abordaron los siguientes temas: demostración de los microorganismos en el medio ambiente y el papel de las micorrizas; producción, comercialización y consumo de champiñones; compostaje y producción de alimentos fermentados. En total, las actividades involucraran alrededor de 65 estudiantes, 5 monitores de la EFA y 24 alumnos de la UFV. Estas intervenciones han proporcionado un estímulo a la curiosidad, antes poco ofrecida, sobre el mundo microbiano y sus aplicaciones, además de instigar el interés por el conocimiento científico.

Palabras-clave: Agricultura Familiar, Microbiología agrícola, Universidad Federal de Viçosa

\section{Introdução}

A extensão universitária caracteriza-se como um processo de construção de relações entre a sociedade e a Universidade, objetivando-se a instituição de práticas cidadãs de pesquisa e ensino (CEPE, 2007). De acordo com esses preceitos, a Universidade não deve ser encarada como proprietária de um saber a ser disponibilizado para a sociedade, envolvendo a transferência unidirecional de conhecimento (ROCHA et al., 2013), mas sim como parte desta sociedade, sensível aos seus principais problemas, prioridades e demandas, caracterizando-se, portanto, como uma universidade cidadã, promotora de inclusão social.

Nesse contexto de cidadania e interdisciplinaridade, a Agroecologia ganha destaque ao valorizar os saberes populares e integrar conhecimentos de várias disciplinas científicas (CARDOSO; FERRARI, 2006; PRATES JÚNIOR et al., 2016, 2017b). Isso significa construir alternativas e possibilitar que as novas gerações de cientistas estabeleçam relações mais inclusivas e efetivas com a sociedade.

$\mathrm{Na}$ Universidade Federal de Viçosa (UFV) existem experiências bem-sucedidas de construção e socialização de conhecimento junto à comunidade, dentre eles o Programa TEIA de Extensão Universitária (BARBOSA et al., 2013) e o Café com Agroecologia (CAFÉ COM AGROECOLOGIA, 2017; PRATES JÚNIOR et al., 2017a), concebidos com o propósito de proporcionar o compartilhamento de conhecimentos e experiências em suas respectivas áreas de atuação. Nesta conjuntura, o Núcleo de Estudos em Microbiologia Agrícola (NEMA) foi criado por estudantes e professores do Programa de 
Pós-Graduação em Microbiologia Agrícola (PPGMBA/UFV) com o objetivo de transformar, integrar, promover e compartilhar experiências de pesquisa, ensino e extensão, relacionadas à Microbiologia (PRATES JÚNIOR et al., 2017b).Vem atuando, portanto, no fortalecimento da Microbiologia não apenas como uma disciplina universitária, mas também como uma ciência que está inserida no dia-a-dia da população, a exemplo de cuidados com saúde e higiene, meio ambiente, agricultura, produção e consumo de alimentos.

Assim, com a perspectiva de fortalecer a troca de saberes com a comunidade regional de Viçosa, o NEMA iniciou o projeto de extensão "A importância da microbiologia para a agroecologia" junto à Escola Família Agrícola (EFA) Puris, localizada na cidade de Araponga-MG. Essa instituição, fundada em 2008, apresenta como proposta a adequação da escola à vida no campo, fortalecendo a valorização da terra pela juventude rural e o desenvolvimento de técnicas agrícolas adequadas à realidade local, tendo a agroecologia como eixo norteador (BARDUNI FILHO; COELHO, 2013).

As EFA surgiram na Itália na década de 1960 e se fundamentam na Pedagogia da Alternância, pensamento nascido no interior da França por volta de 1935, a partir da proposta de agricultores para um modelo de educação que atendesse às necessidades reais dos viventes no meio rural. Essa pedagogia expandiu-se para outros países e continentes a partir de 1950 (FONSECA, 2008). A Pedagogia da Alternância articula atividades práticas e teóricas, em tempos e espaços que se alternam entre a escola e a comunidade na qual os educandos estão inseridos. Representa, portanto, um caminho para viabilizar a relação entre o trabalho produtivo e a formação escolar de jovens trabalhadores rurais (RIBEIRO, 2008).

As EFA são caracterizadas pela responsabilidade das famílias na gestão da escola, pela alternância dos períodos de formação, pela convivência dos jovens em internato e pelo suporte de uma equipe de educadores. Tais preceitos inserem-se nos pilares centrais dessas instituições, que consistem em associações locais, a pedagogia da alternância, a formação integral dos jovens e o desenvolvimento local sustentável (FONSECA, 2008). Os educandos permanecem 15 dias na escola, desenvolvendo atividades curriculares, e 15 dias junto às suas famílias, momento em que compartilham o conteúdo trabalhado na escola e praticam as atividades em casa. Dentre as atividades colaborativas, a EFA Puris conta com apoio de professores e estudantes da UFV e técnicos do Centro de Tecnologias Alternativas da Zona da Mata (CTA-ZM).

Nesse contexto, o NEMA, enquanto espaço organizado para a integração, construção e socialização de conhecimentos, têm atuado junto à EFA Puris, colaborando com a formação de jovens educandos da zona rural e possibilitando que os acadêmicos envolvidos adquiram experiência no uso e readequação do conhecimento científico para ações práticas e sociais. $\mathrm{O}$ presente artigo apresenta os resultados das primeiras intervenções do NEMA junto à EFA Puris, relatando uma experiência que envolve a aplicação de práticas docentes comumente utilizadas na Universidade a uma escola com uma proposta diferenciada de pedagogia no âmbito da Agroecologia.

\section{Procedimentos Metodológicos}

As atividades foram propostas em maio de 2016 por alunos e professores do PPGMBA/UFV (Universidade Federal de Viçosa), Café com Agroecologia - UFV, juntamente com monitores e educandos da EFA Puris, localizada na comunidade de São Joaquim, no município de Araponga-MG. Previamente, foram realizadas reuniões entre monitores da EFA Puris e membros do NEMA para formulação dos objetivos e metas a serem alcançadas com as atividades do Projeto.

As atividades realizadas foram de natureza teóricoprática e, inicialmente, foi adotada uma abordagem da educação formal com aulas expositivas e conteúdos previamente demarcados. Realizaram-se discussões sobre o conteúdo abordado de forma mais difusa e direcionadas para a problematização do cotidiano dos educandos, seguindo a proposta pedagógica de Paulo Freire (FREIRE, 1982; 1985, 2002). Além disso, os momentos de intervalo foram utilizados como espaços de socialização e compartilhamento de experiências, na perspectiva da educação não-formal (GOHN, 2006) entre educandos e monitores da EFA Puris e os acadêmicos envolvidos. Nas atividades práticas foram utilizados instrumentos e equipamentos laboratoriais para preparo e observação de material biológico, como lâminas a fresco, bem como a realização de pequenos experimentos, dentro dos seguintes temas:

> Intervenção 1: Demonstração dos micro-organismos no ambiente e o papel das micorrizas;

> Intervenção 2: Produção, comercialização e consumo de cogumelos;

$>$ Intervenção 3: Compostagem e produção de alimentos fermentados.

As ações incluíram estratégias de avaliação por meio de diálogos após o fim das atividades e fichas de avaliação preenchidas pelos educandos da EFA Puris, visando ao aprimoramento de atividades futuras, bem como a produção de informações a fim de contribuir para a disponibilização de materiais didáticos e/ou científicos acerca da importância da Microbiologia. Posteriormente às atividades, os membros do NEMA organizaram reuniões para planejamento e avaliação qualitativa das atividades realizadas, debatendo o conteúdo apresentado e as dificuldades e perspectivas futuras.

As atividades realizadas contaram com a participação de aproximadamente 65 alunos do Ensino Médio e 5 monitores da EFA Puris, e 24 acadêmicos da UFV, dentre 16 pós-graduandos em Microbiologia Agrícola, 2 pósgraduandos em Agroecologia, 2 técnicos de laboratório, 2 estudantes de graduação (Licenciatura em Educação do 
Campo e Agronomia), e 2 professores do Departamento de Microbiologia.

A primeira intervenção foi realizada em junho de 2016 com as turmas de $2^{\circ}$ e $3^{\circ}$ anos (aproximadamente 45 educandos). Ao iniciar as atividades, os integrantes do NEMA e do Café com Agroecologia se apresentaram e relataram as ações e objetivos de cada um dos grupos. Os monitores presentes narraram a história de criação e a dinâmica educacional da EFA Puris. $O$ tema foi "Demonstração dos micro-organismos no ambiente e o papel das micorrizas", com explicação teórica dos principais grupos de micro-organismos e suas funções: simbiontes, patógenos, decompositores e sua utilização na produção de alimentos. Como atividades práticas, visualizaram com auxílio de microscópio e de estereomicroscópio colônias e lâminas permanentes e a fresco, nódulos em leguminosas e estruturas micorrízicas. Realizaram, ainda, uma caminhada guiada no entorno da EFA Puris com o objetivo de observar a presença de micro-organismos em composteira, folhas com sintomas de doenças, cogumelos e líquens (Figura 1A e B).

Os educandos participaram de uma apresentação teórica sobre simbiose e associações micorrízicas, que permitiu a observação de raízes de cenoura transformadas e associadas com fungos micorrízicos, esporos e estruturas de fungos micorrízicos em raízes diafanizadas e coradas, rede de Hartig em raízes de eucalipto e pélotons em raízes de orquídeas. Após essas atividades, foi realizada uma discussão da dissertação de Mestrado "Comunidade de fungos micorrízicos arbusculares em diferentes sistemas de manejo do cafeeiro", do Programa de Pósgraduação em Agroecologia da UFV. Após as discussões, os participantes puderam dialogar sobre a experiência das atividades, no qual destacaram a primeira experiência com o uso de microscópio e a visualização de microorganismos. Os acadêmicos, por sua vez, destacaram a oportunidade de conhecer a dinâmica, história e pedagogia adotada pela EFA Puris.

A segunda intervenção, realizada em outubro de 2016 com as turmas do $1^{\circ}, 2^{\circ}$ e $3^{\circ}$ anos do ensino médio (aproximadamente 65 educandos), apresentou como tema "Produção, comercialização e consumo de cogumelos". No primeiro momento houve uma explicação teórica sobre fungos e seu papel no ambiente, destacando sua função como decompositores, as diferenças entre cogumelos comestíveis e não comestíveis, o uso de diferentes tipos de resíduos agroindustriais como substratos para seu cultivo, os benefícios da utilização na alimentação, formas de preparo para consumo e comercialização de cogumelos. Houve discussões correlacionando o tema com a agroecologia, uma vez que cogumelos comestíveis são alimentos funcionais que permitem diversificar a produção, aproveitar diversos resíduos e gerar renda.Na atividade prática, inocularam shiitake (Lentinula edodes) em toras de eucalipto e hiratake (Pleurotus ostreatus) em bagaço de cana de açúcar, sendo disponibilizado um kit de cultivo para cada um dos educandos. Após a realização das atividades práticas, houve a degustação dos cogumelos shiitake e hiratake refogados com vegetais. Durante conversas informais, percebeu-se, por parte dos alunos, desde empolgação até certo receio ao comer os cogumelos refogados. A avaliação das fichas evidenciou que a grande maioria dos educandos aprovou a atividade, incentivando a continuidade do projeto e relatando que o mesmo teve impactos significativos em seu cotidiano (Figura 1C e D).

Em junho de 2017 foi realizada a terceira intervenção, abordando o tema "Compostagem e produção de alimentos fermentados" com a turma do $2^{\circ}$ ano (aproximadamente 25 educandos). A fim de auxiliar na dinâmica do curso, foi preparado um material didático sobre compostagem e produção de alimentos fermentados (iogurte e queijo), o qual foi distribuído para cada um dos educandos. Na parte da manhã foram realizadas atividades teóricas e práticas sobre compostagem, destacando-se os principais grupos de micro-organismos, seus habitats e suas funções. Destacou-se também o papel dos micro-organismos como decompositores no processo de compostagem, os fatores que podem afetar a atividade destes e a qualidade do composto final, a exemplo da relação Carbono/Nitrogênio $(\mathrm{C} / \mathrm{N})$, umidade e temperatura. Além disso, enfatizou-se a importância da compostagem para a produção de alimentos mais saudáveis e a relação desta prática com atividades agroecológicas, como o reaproveitamento de resíduos, melhoria da qualidade do solo, diminuição do uso de agrotóxico e produção de alimentos mais saudáveis.

No segundo momento, as atividades começaram com a apresentação teórica sobre as Boas Práticas de Fabricação de Alimentos e a participação dos microorganismos nos processos fermentativos para a produção de alimentos, como iogurte, kefir e queijo. Em seguida, os educandos participaram de atividades práticas para a produção de queijo e iogurte, evidenciando a função dos micro-organismos fermentadores e interagindo com perguntas e curiosidades sobre o processo de produção, uma vez que estas são práticas comuns para muitas famílias de educandos da EFA Puris. Houve espaço para a degustação do queijo e do iogurte produzidos durante as atividades (Figura 1E e F).

Por fim, os educandos da EFA Puris e os acadêmicos puderam dialogar sobre as atividades, levantando aspectos positivos como a oportunidade de visualizar e aprender sobre as funções dos micro-organismos, o material didático disponibilizado e a oportunidade de entender mais sobre a fabricação de produtos fermentados; aspectos negativos também foram pontuados, como a dificuldade de entendimento de alguns termos técnicos e o longo tempo das atividades. 
A)

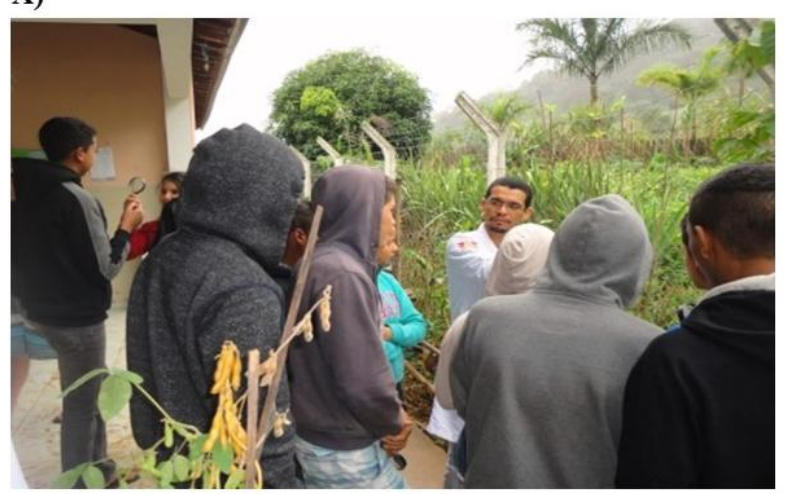

C)

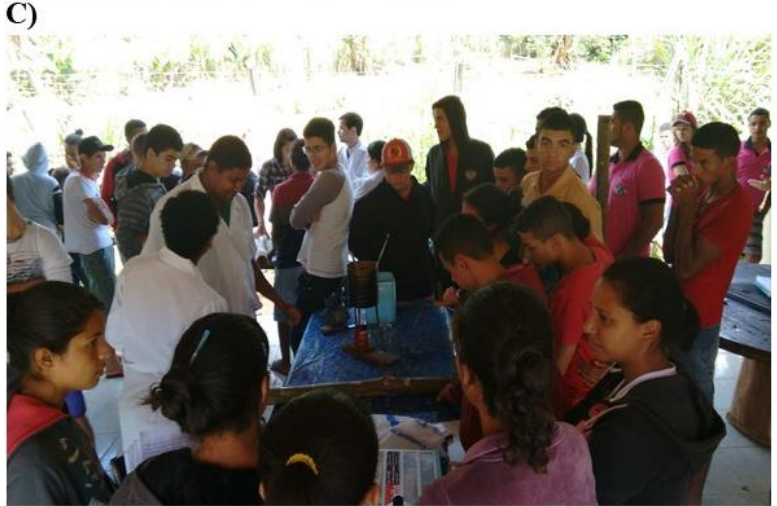

E)

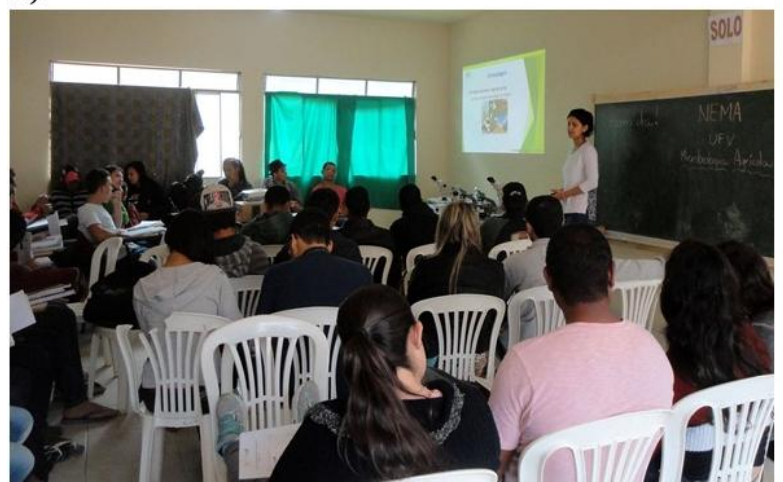

B)

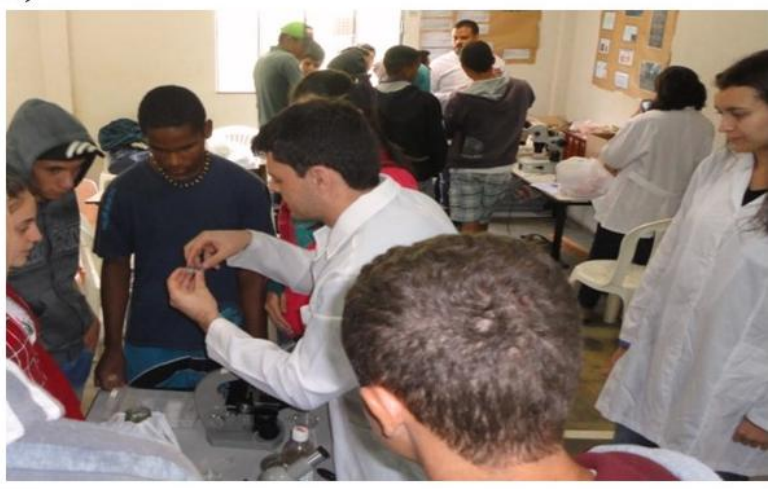

D)

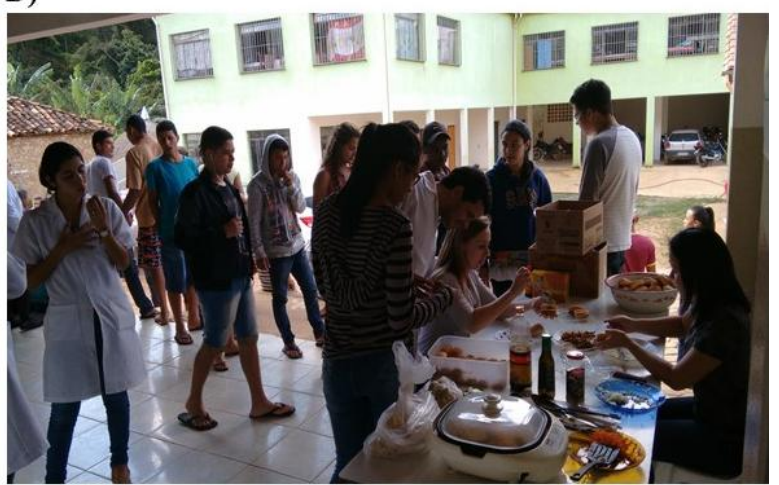

F)

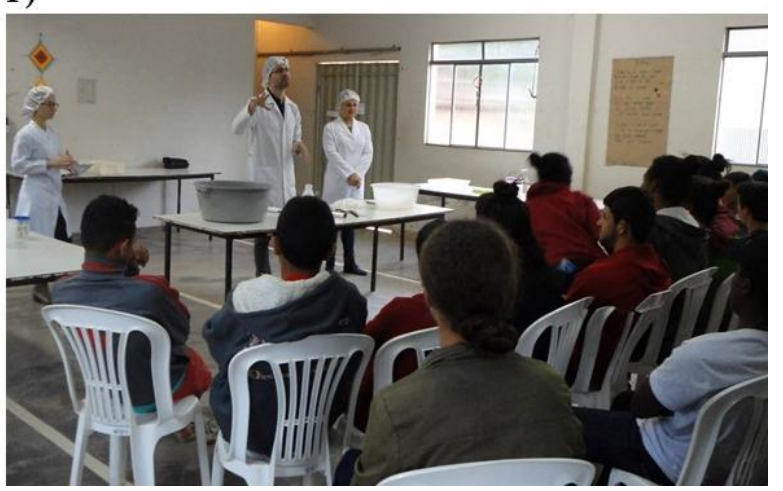

Figura 1 - Intervenções realizadas pelo NEMA na EFA Puris. Primeira intervenção: A) Observação de nódulos com rizóbios em raízes de leguminosas; B) Preparo de lâmina à fresco para visualização de micorrizas de orquídea. Segunda intervenção: C) Preparo para inoculação de toras com sementes de Shitakii; D) Formas de preparo e degustação de cogumelos. Terceira intervenção: E) Apresentação sobre compostagem; F) Atividade prática de produção de queijo e iogurte.

\section{Discussão}

O grande número de acadêmicos envolvidos no projeto demonstra o interesse e a importância desse tipo de atividade de extensão, em que o diálogo e a interdisciplinaridade norteiam as ações. $\mathrm{O}$ projeto em questão surgiu como demanda dos agricultores envolvidos no trabalho de dissertação "Comunidade de fungos micorrízicos arbusculares em diferentes sistemas de manejo do cafeeiro" (PRATES JÚNIOR, 2014) que apontaram uma forma de devolução de resultados para as famílias dos agricultores da região. Assim, o NEMA assumiu a iniciativa de incorporar o ensino e extensão à produção de conhecimento científico e formação de pessoas (ROCHA et al., 2013), possibilitando a troca de conhecimento popular e acadêmico.

A primeira intervenção permitiu que educandos da EFA Puris, integrantes do NEMA e Café com Agroecologia UFV encontrassem pontos comuns, como a construção de espaços coletivos criados para ampliar as ações. Descobriu-se que a história de criação da EFA Puris remonta à "conquista da terra" iniciada a partir de 1979 , por meio da organização coletiva, identidade e empoderamento dos agricultores, que em parceria com o Centro de Tecnologias Alternativas (CTA), iniciaram a adoção de modelos agroecológicos de produção (ALVES, 2006), resultando em significativas transformações sociais.

No contexto da educação não formal percebeu-se a reconstrução de concepções, autoavaliação e 
reconhecimento do papel do outro (GOHN, 2006). Nas reuniões de planejamento e avaliação, os acadêmicos sinalizaram o aprendizado de informações úteis e práticas sobre agropecuária, bem como valores sociais do meio rural, a exemplo da importância da colheita do café no calendário escolar e a oração ecumênica feita em 2008 pela primeira turma de educandos:

Obrigado, Senhor, pela terra onde produzimos nossos alimentos. Queremos alcançar a sustentabilidade praticando a agroecologia. Juntos, com união e força de vontade, alcançaremos nossos objetivos. Queremos agradecer e pedir a benção para todas as mãos que contribuíram pelo alimento que sacia nossa fome, que nunca nos falte alimento, nem a nossos irmãos. Amém!

Outro aspecto interessante observado na EFA Puris é a participação efetiva dos monitores na definição dos temas de interesse dos educandos, tendo como base a pedagogia de Paulo Freire (FREIRE, 2002), no sentido de assumir uma perspectiva social na qual se aprende ao ensinar, colocando em prática a capacidade de indagar e comparar. Além disso, as atividades da escola são organizadas em escalas - com as diferentes tarefas divididas igualmente entre homens e mulheres, sendo um aspecto diferenciado da EFA Puris (BARDUNI FILHO; COELHO, 2013). Portanto, existe não apenas o reconhecimento dos sistemas de valores do meio rural, mas também a transformação de valores, como ocorreu a partir da discussão de igualdade de gênero na divisão de tarefas.

Os educandos da EFA Puris aprenderam sobre os detalhes do mundo microbiano, e a relação desses microorganismos com a agroecologia: da produção ao consumo de alimentos. As atividades permitiram o desenvolvimento de habilidades e contribuiu para a popularização do ensino de microbiologia, de forma acessível e adequada à realidade local. A introdução de noções práticas básicas de Microbiologia ofereceu uma visão ampla dos microrganismos, relacionando-os com o dia a dia e ampliando a correlação entre o embasamento teórico e a realidade (KIMURA et al., 2013).

Os educandos perceberam também que os microorganismos estão dispersos em todo o ambiente e que medidas simples, como a lavagem das mãos, diminui os riscos da contaminação microbiana, assim como o armazenamento dos alimentos sob refrigeração reduz o crescimento de bactérias patogênicas e deteriorantes. Estas intervenções permitiram que os educandos adquirissem conhecimentos teóricos e suas aplicações na prática, instigando-os para que as ações realizadas de forma rotineira fossem pensadas de forma científica, visando principalmente à interação dos microorganismos nas práticas cotidianas.

Ainda que o mundo microbiano possa parecer bastante abstrato, uma vez que não se pode percebê-los de forma mais direta por meio dos sentidos - o que dificulta seu aprendizado - é um tema de grande relevância para a sociedade (CASSANTI et al., 2008). Nesse caso, o microscópio tornou-se um instrumento didático importante, que permitiu aos educandos visualizarem os micro-organismos.

Os educandos da EFA Puris trabalham com a produção de micro-organismos eficientes, obtidos em fragmentos de mata, utilizando isca a base de arroz cozido sem sal, seguido por fermentação em melaço de cana-de-açúcar em condições anaeróbicas (BONFIM et al., 2011), vermicompostagem, produção e consumo de alimentos que têm relação direta e indireta com a atividade microbiana. Deste modo, os temas desenvolvidos nestas intervenções geraram discussões e motivaram os educandos a atuarem como multiplicadores de técnicas agrícolas que promovam o manejo e uso de microorganismos benéficos, como micorrizas, bactérias fixadoras de nitrogênio, micro-organismos eficientes, cogumelos comestíveis e micro-organismos fermentadores.

A distribuição de kits para a produção de cogumelos, por exemplo, permitiu que os educandos pudessem socializar a experiência de produção e consumo de cogumelos com seus familiares. O mesmo ocorreu com os grãos de kefir, que foram disponibilizados para que pudessem cultivar em casa uma bebida probiótica, composta por pelo menos 30 estirpes de bactérias lácticas e leveduras (LAUREYS e VUYST, 2014), possibilitando o uso de um alimento saudável e de fácil preparo pela comunidade.

Dentre os principais desafios das intervenções destacamse a dificuldade em conciliar o calendário acadêmico da UFV com o da EFA Puris, que funciona em regime de alternância; a distância entre Viçosa e Araponga (aproximadamente $50 \mathrm{~km}$ ), o que demanda o planejamento das atividades para os dois turnos, a fim de otimizar as intervenções; a falta de financiamento, uma vez que o custeio ocorre por meio de contribuições dos membros do NEMA e apoio logístico da EFA Puris; a dificuldade em conciliar o uso de valores da cultura acadêmica na interpretação e abordagem didática utilizada na EFA Puris, a exemplo do uso de alguns termos técnicos de microbiologia, conforme discutido com os educandos da EFA Puris a partir da segunda intervenção. Neste caso, a estratégia adotada foi tentar readequar a linguagem e explanar os significados dos termos, bem como confeccionar e disponibilizar material didático na terceira intervenção. Deste modo, é preciso considerar estratégias para apresentar a ciência de um modo menos operacional, tornando-a mais lúdica e próxima ao contexto sociocultural dos educandos.

Ressaltamos, por fim, a perspectiva de divulgar as experiências e incentivar outras iniciativas de extensão universitária, além de exercitar a docência em um contexto transformador, ampliando o diálogo acadêmico com outros setores sociais. Em parceria com outros grupos e instituições de ensino, o NEMA pretende continuar a divulgação da microbiologia para a comunidade em geral, democratizando o processo de ensino-aprendizagem na região de Viçosa. 


\section{Considerações Finais}

A integração entre educação formal, não formal e a divulgação de pesquisas científicas conduz à aprendizagem como prática social e gera conhecimentos e vivências de situações-problema em trabalhos coletivos, dentre todos os agentes envolvidos. Ampliar o conhecimento a partir da vivência-problema é um dos principais meios para estimular e atender às expectativas tanto do educador quanto do educando, que se revelam na combinação de métodos participativos preconizados pela agroecologia, pedagogia freiriana e da alternância. As atividades práticas de microbiologia proporcionam reflexões e questionamentos que possibilitam a mudança das ações e práticas rotineiras, as quais podem ser ampliadas para a comunidade. Assim, os educandos passam a ter uma visão mais ampla e crítica sobre a Microbiologia e sua relação com a Agroecologia, compreendendo seu papel social. Essas ações extensionistas possibilitam a aproximação do meio científico com a sociedade, favorecendo a democratização do conhecimento.

\section{Agradecimentos}

À Escola Família Agrícola (EFA) Puris, Araponga MG, pela parceria e troca de conhecimentos com o NEMA e o Café com Agroecologia - UFV, possibilitando vivências de ensino-aprendizado. Aos agricultores da região de Araponga, verdadeiros protagonistas na construção da EFA Puris. Aos demais membros do NEMA, ao Programa de Pós-graduação em Microbiologia Agrícola e ao Programa de Pós-graduação em Agroecologia da UFV pelo fomento à pesquisa, ensino e extensão, resultando na realização das atividades e elaboração do presente artigo.

\section{Contribuições de cada autor}

P.P.J., M. C. S. S., participaram da elaboração do projeto, execução das atividades teóricas e práticas e da redação e revisão do manuscrito; L. A. M, K. S. A., I. G. O P., C. A. S., J. G. P.M. participaram da execução das atividades teóricas e práticas e da redação e revisão do manuscrito.

\section{Referências}

ALVES, M. A. A "conquista da terra": (re)produção social e (re)construção histórica entre agricultores familiares do município de Araponga - MG. Mana, v. 12, n. 2, p. 269-283, 2006.

BARBOSA, W. A.; ZANELLI, F. V.; LOPES, L. S.; CRUZ, N. A. C.; CONTE, G. M.; MOREIRA, F. O. CARDOSO, I. M. Programa Teia: trocando saberes e reinventando a universidade. Agriculturas, v. 10, p.7-11, 2013.

BARDUNI FILHO, J.; COELHO, F. M. C. Sexualidade e afetividade na EFA-Puris, MG: o controle dos pais e a religiosidade das famílias. Série-Estudos, n. 35, p. 185198, 2013.

BONFIM, F. P. G.; HONÓRIO, I. C. G.; REIS, I. L.; PEREIRA, A. J.; de SOUZA, D. B. Caderno dos Microrganismos Eficientes. 2011. (Desenvolvimento de material didático ou instrucional - Cartilha). Disponível em < http://estaticog1.globo.com/2014/04/16/cadernodos-microrganismos-eficientes.pdf $>$. Acesso 21 set. 2017.

CAFÉ COM AGROECOLOGIA. Pós-graduação em Agroecologia. Disponível em < http://

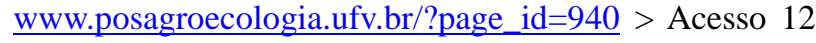
mar. 2017.

CARDOSO, I. M.; FERRARI, E. A. Construindo o conhecimento agroecológico: trajetória de interação entre ONG, universidade e organizações de agricultores. Agriculturas, v. 3, n.4, p. 28-32, 2006.

CASSANTI, A. C.; ARAÚJO, E. E.; URSI, S. Microbiologia democrática: estratégias de ensinoaprendizagem e formação de professores. Disponível em: < http://botanicaonline.com.br/geral/arquivos/ Cassantietal2008\%20microbiologia.pdf >. Acesso 10 set. 2017.

CEPE-CONSELHO DE ENSINO, PESQUISA E EXTENSÃO. Resolução $\mathrm{N}^{\circ}$ 7, de 2007. Aprova a Política de Extensão da UFV, que passa a fazer parte integrante desta Resolução. Viçosa: Universidade Federal de Viçosa, 5 de dezembro de 2007.

FREIRE, P. Pedagogia do oprimido. Rio de Janeiro: Paz e Terra, 1982.

FREIRE, P. Educação como prática de liberdade. Rio de Janeiro: Paz e Terra, 1985.

FREIRE, P. Pedagogia da autonomia: saberes necessários à pratica educativa. São Paulo: Paz e Terra, 2002.92p

FONSECA, A. M. Contribuições da Pedagogia da Alternância para o desenvolvimento sustentável: trajetórias de egressos de uma Escola Família Agrícola. Dissertação de Mestrado, Faculdade de Educação, Universidade Católica de Brasília, Brasília, 2008.

GOHN, M. G. Educação não-formal, participação da sociedade civil e estruturas colegiadas nas escolas. Ensaio: Avaliação e Políticas Públicas em Educação, v. 14, n. 50, p. 27-38, 2006.

KIMURA, A. H. et al. Microbiologia para o ensino médio e técnico: contribuição da extensão ao ensino e aplicação da ciência. Revista Conexão (UEPG), v. 9, n. 2, p. 254-267, 2013.

LAUREYS, D.; VUYST, L. Microbial species diversity, community dynamics, and metabolite kinetics of water Kefir fermentation. Applied and Environmental Microbiology, v. 80, n.8, AEM. 03978-13, 2014. 
PRATES JÚNIOR, P. Comunidade de fungos micorrízicos arbusculares em diferentes sistemas de manejo do cafeeiro. Dissertação de Mestrado, Programa de Pós-graduação em Agroecologia, Universidade Federal de Viçosa, Viçosa, 2014.

PRATES JÚNIOR, P.; CUSTÓDIO, A. M.; GOMES, T. O. Agroecologia: reflexões teóricas e epistemológicas. Revista Brasileira de Agroecologia, v.11, n. 3, 2016.

PRATES JÚNIOR, P.; PEREIRA, A. J.; SANTANA, F. C.; dos SANTOS, L. F.; do CARMO, D. L.; CASALI, V. W. D.; PRIORE, S. E. Café com Agroecologia: integrando conhecimentos. Revista Elo: Diálogos em Extensão, v.6, n. 3, 2017a.

PRATES JÚNIOR, P.; CERQUEIRA, A. E. S; VELOSO, T. R. G.; CORREIA, H. L. N.; KASUYA, M. C. M. Núcleo de Estudos em Microbiologia Agrícola (NEMA): integração e multiplicação de ações e conhecimentos. Revista Elo: Diálogos em Extensão, v. 6, n. 3, 2017b.

RIBEIRO, M. Pedagogia da alternância na educação rural do campo: projetos em disputa. Educação e Pesquisa, v. 34, n. 1, p. 27-45, 2008.

ROCHA, P. L. B.; EL-HANI, C. N.; PARDINI, R. Extensão como filosofia para o preenchimento da lacuna pesquisa-aplicação na Universidade. Revista Caititu, v. 1, n.1, p.7-16, 2013.

\footnotetext{
Como citar este artigo:

PRATES JUNIOR, P.; DA SILVA, M. C. S.; MELO, R. C. C.; DE LIMA, L. A.; ARAÚJO, K. S.; PRADO, I. G. O.; SALGADO, C. A.; MARTIN, J. G. P. A microbiologia no contexto da agroecologia: atividade de extensão junto à Escola Família Agrícola Puris. Revista Brasileira de Extensão Universitária, v. 9, n. 2, p. 75-82, 2018. Disponível em: < https://periodicos.uffs.edu.br/index.php/RBEU/article/view/757 $\underline{6 / p d f}>$
} 